\title{
Why Should We Publish Papers?
}

To get to know, to discover, to publish—this is the destiny of the scientist

—Francois Arago, French Mathematician, Physicist and Astronomer (1786-1853)

\subsection{What Is Academic Medicine?}

Academic medicine traditionally includes three principal pursuits, i.e., educating doctors and biomedical scientists, discovering the causes and cures of illness, and using knowledge to improve patient care. Teaching, research, and service are the triad of academic medicine (Fig. 2.1). It has also been described as 'the capacity of the system for health and health care to think, study, research, discover, evaluate, innovate, teach, learn, and improve' [1].

\subsection{What Are the Duties of a Doctor in an Academic Institution?}

An academic doctor plays many roles like clinician, teacher, administrator, mentor, examiner, and researcher during his or her lifetime (Fig. 2.2). However, his/her most important role is patient care followed by teaching and finally research. Thus, research and publication are important aspects of academic medicine but combining academics with patient care are two full-time jobs that many physicians are unable to pursue.

As a clinician, the first priority is to treat a patient's illness. This involves the science as well as the art of practicing medicine. A clinician in an academic institution should follow the highest standards and guidelines for practice so that his/her 
Fig. 2.1 Components of academic medicine

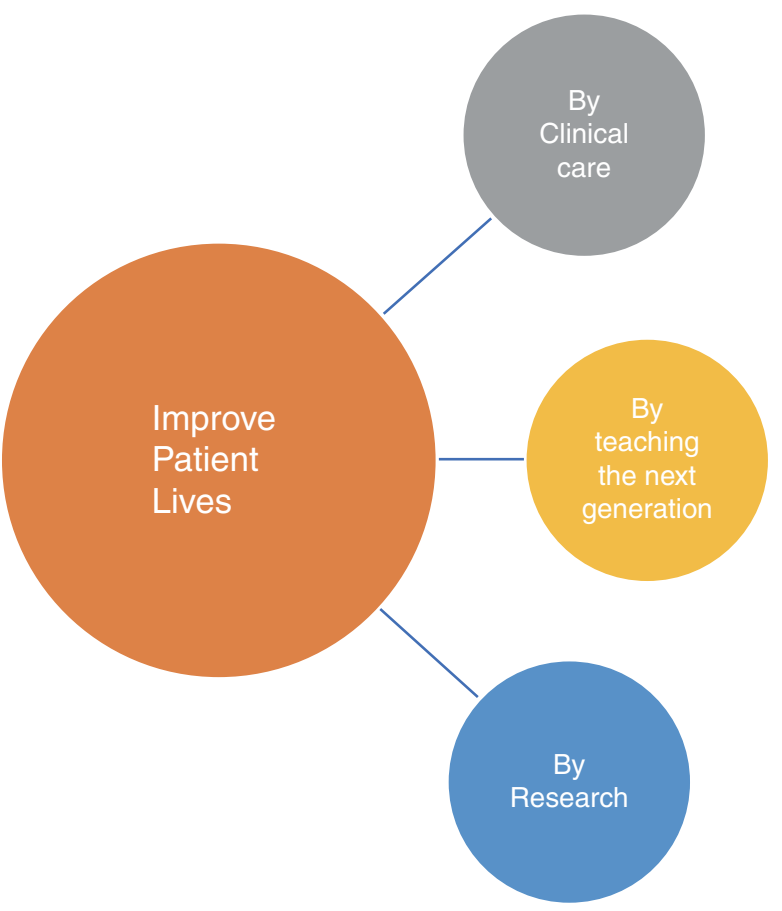

Fig. 2.2 Role of an academic doctor

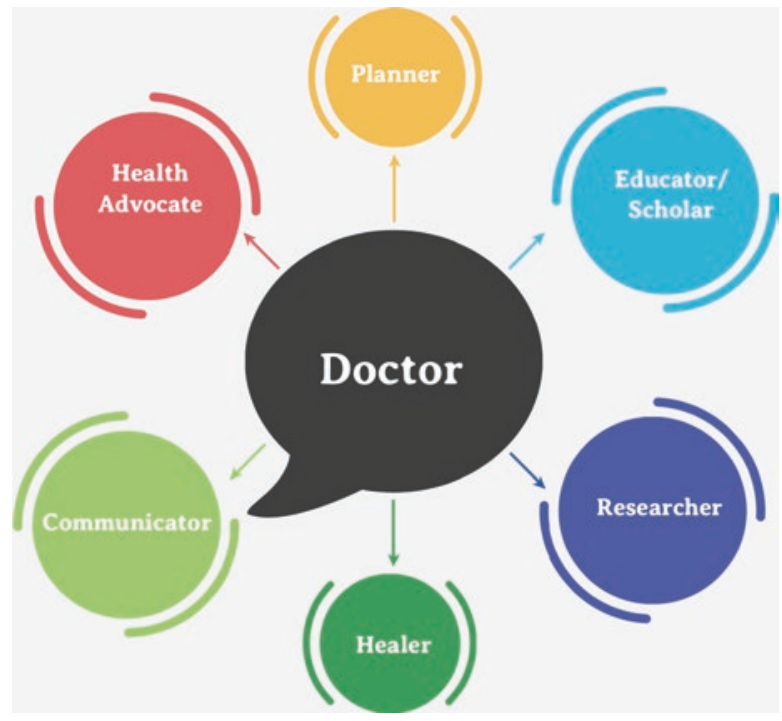


students can imbibe these qualities. The clinical care of patients is taxing, especially in private hospitals where patients are more demanding than they are in public institutions.

Academics provides a physician multiple roles like the opportunity to teach the next generation of doctors, provide comprehensive care to patients, and opportunities for research. As a teacher, he or she may be involved in lectures, case presentations, journal clubs, and topic discussions. However, his/her greatest quality should be a passion for teaching. Being a physician in an academic institution also has a major impact on medical students who look upon their teachers as examples to follow. Anne Beal of the Commonwealth Fund stated that 'medical school faculty set research agendas, influence medical education and yet serve as role models for the recruitment and retention of students' [2].

\subsection{Is Publication in Medical Journals a New Phenomenon?}

'The purpose of research is to publish'-Michael Faraday English Physicist and Chemist (1791-1867)

Scientific publication began in 1660 with the Journal de Scavans in France and the Philosophical Transactions of the Royal Society of London. Henry Oldenburg was the first appointed secretary, i.e., editor, in charge of managing the 'correspondence' between the Society and the rest of the scientific world (Fig. 2.3) [1]. Since then there has been an exponential surge in publications in the field of medicine, the number of articles have increased and so have the journals which now may number more than 30,000. The main role of medical research articles has always been to inform other doctors and the general public about the progress of science. However,
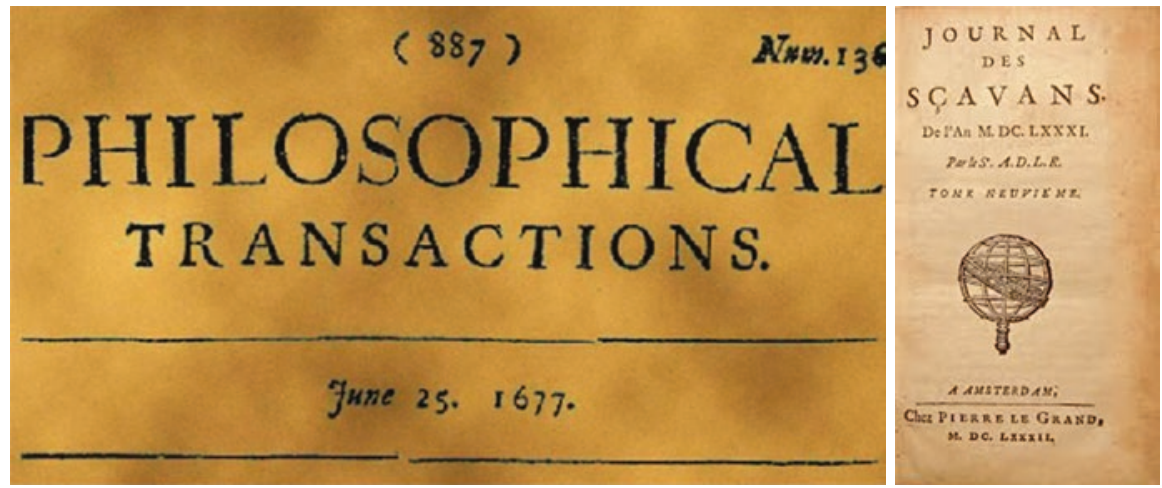

Fig. 2.3 Image of the cover of the first medical journal 
in the current competitive academic environment, more articles are probably published so that authors can gain colleague approbation and faculty promotion.

\subsection{What Are the Main Reasons for Publications?}

These are disseminating the progress of knowledge, personal credit, gaining recognition for a department or institution, and improving patient care. Moe et al. have likened publication to a 'golden egg'. They suggest that the reasons for publication can be summarized in a 'SULTAN pyramid' (amplified below) — to acquire a degree forming the base of the pyramid (Fig. 2.4) [3].

- S-Study requirement for obtaining degrees like Doctor of Medicine or Master of Surgery (MD/MS), Diplomate of the National Board of Examinations (DNB), or Doctor of Philosophy (PhD).

- $\mathbf{U}-$ Requirement for higher faculty posts in academic institutions, salary hikes, or to improve career prospects.

- L-Long-term sustainability of an academic career-called 'tenure' in America.

- T-Achieving a position like a departmental head, dean, and director.

- A-Advancement of health, education, and economic policies.

- $\mathbf{N}-$ Name and fame in society and among one's family and colleagues.

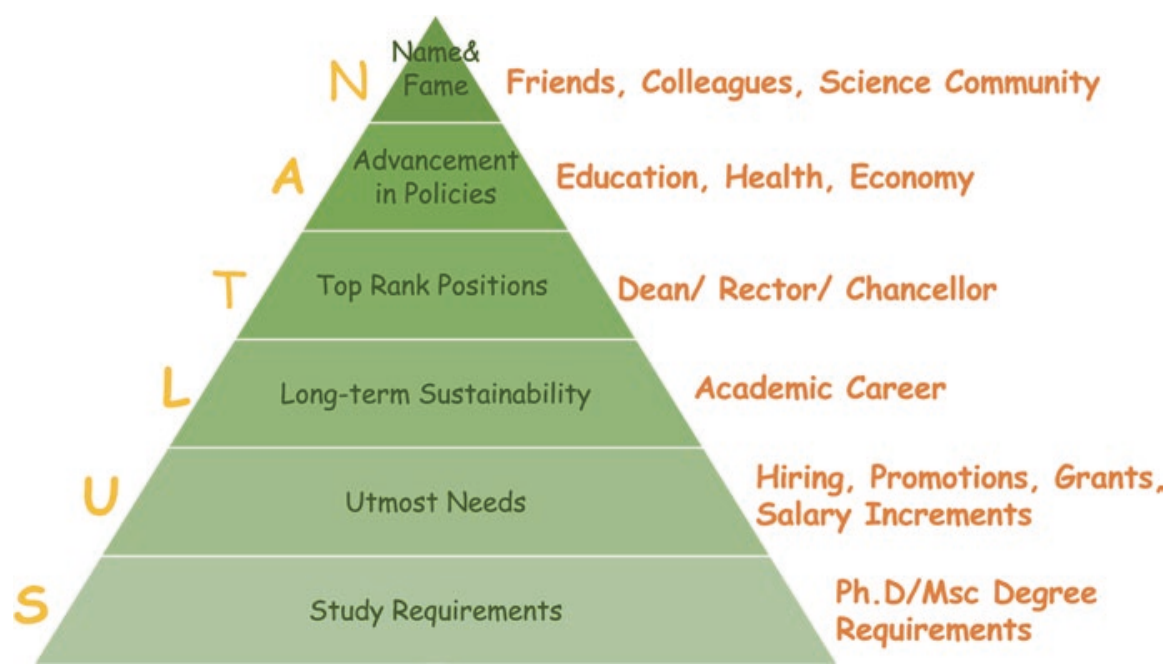

Fig. 2.4 Why we should publish? 


\subsection{Are There Any Other Reasons for Publications?}

Some mention that the main reason why we publish is to improve our Curriculum Vitae and fulfilling criteria for recruitment [4]. The main advantage of publication therefore can also be to further one's career [5].

To the above, we would also like to add a financial reason. In this triad of name, fame, and money, we feel the maximum gain is in personal growth from being a nonentity to an author, from being an ordinary person in a crowd to a leader, to whom people will look for help. You will also become more confident on the professional front and get more referrals from your colleagues.

Publication also increases collaboration between different institutions, which may also involve some injection of finances [6]. You will get an opportunity to travel to present your work in various conferences here and abroad and meet the leaders in your field.

\subsection{Does Publishing Negative Studies Also Give You Fame?}

Sharing negative results does not mean making a good story out of a bad one, that the results are less important, or that they should remain unpublished [7]. But the reality is that if the results of a scientific paper are negative it will be difficult to find acceptance of your submission by a journal editor. However, some of the most important publications in academic medicine have a negative outcome.

\subsection{Fraudulent Publication and the Case of Dr. John Darsee?}

John Darsee was a physician and investigator who had a long list of publications in leading journals. He seemed, on the surface, to be having a successful career in the field of research in cardiology and a former administrator described him to be 'one of the most remarkable young men in American Medicine'. At the age of 33 years, Darsee was offered a faculty position at the Harvard Medical School in Boston but the trajectory of his career quickly began to collapse when one day his colleagues caught him juggling with the data in a study on heart attacks. There was subsequently an enquiry against him which found scientific delinquency on a large scale. He was punished by being expelled from his institution, banned from receiving any grant money for ten years and all his manuscripts were withdrawn from the medical literature. He eventually expressed regret for publishing 'inaccuracies and falsehoods' [8]. The Darsee syndrome is named after him reflects the state of how doctors are pressurized to 'Publish or Perish'. 


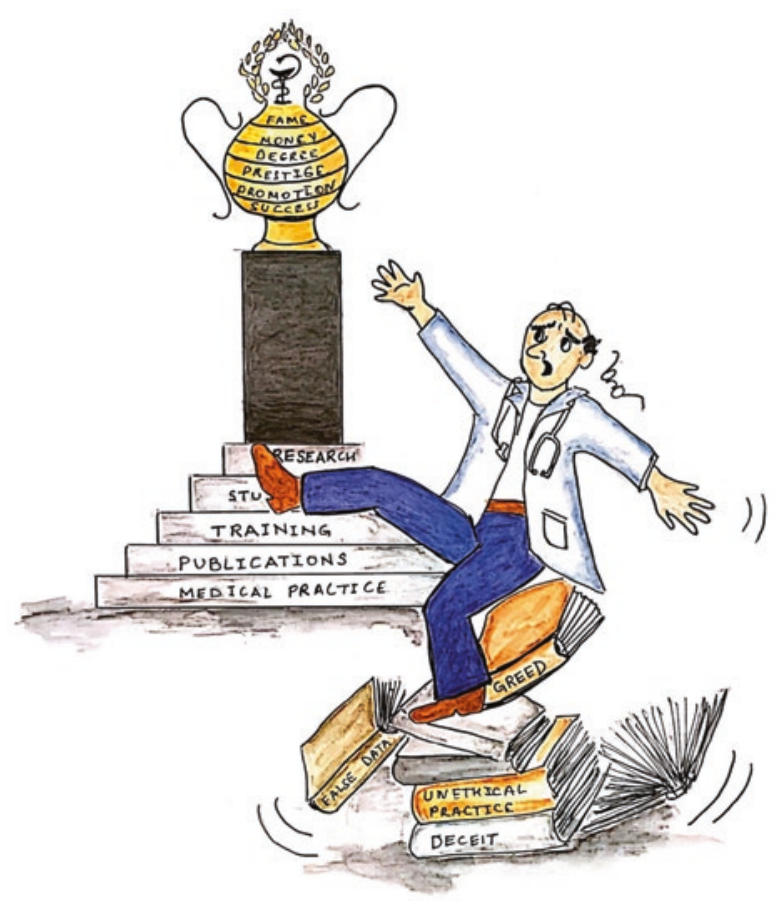

This happened in 1970. However, since then the pressure to publish continues to lead to the fabrication of data. Recently during the present COVID pandemic two papers published in reputed journals were retracted which were based on 'doubtful' data which were untraceable. These were 'Cardiovascular Disease, Drug Therapy, and Mortality in COVID-19' in the New England Journal of Medicine [9] and 'Hydroxychloroquine or Chloroquine with or without a macrolide for treatment of COVID-19: a multinational registry analysis' in the Lancet [10]. Both happened in the early part of 2020 [11]. Although, the publication is necessary as an academic physician you should always follow the highest ethical standards in all your activities-patient care, teaching, and research.

\subsection{Conclusions}

- Academic medicine involves patient care, teaching, research, and publication.

- We publish to get degrees, acquire fame, share knowledge, and get faculty promotions.

- Both positive or negative results help to build knowledge.

- Unethical practices should be strictly avoided as they can ruin careers and lead to much harm. 


\section{References}

1. Marta MM. A brief history of the evolution of the medical research article. Clujul Med. 2015;88(4):567-70.

2. Healthcare workforce diversity: developing physician leaders. https://www.commonwealthfund.org/publications/publication/2003/oct/healthcare-workforce-diversity-developingphysician-leaders. Accessed 8 Feb 2021.

3. Meo SM. Anatomy and physiology of a scientific paper. Saudi J Biol Sci. 2018;27:1278-83.

4. Rawat S, Meena S. Publish or perish: where are we heading? J Res Med Sci. 2014;19:87-9.

5. Peh W. Scientific writing and publishing: its importance to radiologists. Biomed Imaging Interv J. 2007;3:e55.

6. Haruna K, Akmar Ismail M, Damiasih D, Sutopo J, Herawan T. A collaborative approach for research paper recommender system. PLoS One. 2017;12:e0184516.

7. Matosin N, Frank E, Engel M, Lum JS, Newell KA. Negativity towards negative results: a discussion of the disconnect between scientific worth and scientific culture. Dis Model Mech. 2014;7:171-3.

8. John Darsee. Wikipedia. https://en.wikipedia.org/wiki/John_Darsee. Last Accessed 8 Feb 2021.

9. Mehra MR, Desai SS, Kuy S, Henry TD, Patel AN. Cardiovascular disease, drug therapy, and mortality in Covid-19. N Engl J Med. 2020;382(25):e102.

10. Mehra MR, Desai SS, Ruschitzka F, Patel AN. RETRACTED: hydroxychloroquine or chloroquine with or without a macrolide for treatment of COVID-19: a multinational registry analysis. The Lancet. 2020;736(20):31180-6. https://doi.org/10.1016/S0140-6.

11. Two elite medical journals retract coronavirus papers over data integrity questions. https:// www.sciencemag.org/news/2020/06/two-elite-medical-journals-retract-coronavirus-papersover-data-integrity-questions. Last Accessed 13 June 2020.

Open Access This chapter is licensed under the terms of the Creative Commons Attribution 4.0 International License (http://creativecommons.org/licenses/by/4.0/), which permits use, sharing, adaptation, distribution and reproduction in any medium or format, as long as you give appropriate credit to the original author(s) and the source, provide a link to the Creative Commons license and indicate if changes were made.

The images or other third party material in this chapter are included in the chapter's Creative Commons license, unless indicated otherwise in a credit line to the material. If material is not included in the chapter's Creative Commons license and your intended use is not permitted by statutory regulation or exceeds the permitted use, you will need to obtain permission directly from the copyright holder.

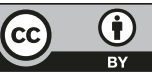

